\title{
Um outro nome para uma realidade em mudança
}

Raquel Braga*

1 Associação Portuguesa de Médicos de Clínica Geral mudou de nome. A modificação do nome para Associação Portuguesa de Medicina Geral e Familiar (APMGF) foi votada por unanimidade, em Assembleia Geral, a 26 de Novembro de 2011. Dá-se início a mais um capítulo na história desta Associação, que é mais ou menos indissociável do percurso da Medicina Geral e Familiar portuguesa.

Esta alteração, ansiada por muitos dos médicos de família que sempre lutaram pela afirmação da especialidade, ocorre, naturalmente, num momento em que a própria Associação se encontra em evolução, ansiando por consolidar a sua maturidade associativa e o seu papel de sociedade científica.

Nos últimos 6 anos, vivemos tempos de transformações na Medicina Geral e Familiar e, podemos dizê-lo com objectiva segurança, globalmente essas mudanças foram positivas para todos nós.

A reforma dos Cuidados de Saúde Primários, iniciada em 2005, ${ }^{1}$ a aprovação de programa de internato de Medicina Geral e Familiar, ${ }^{2}$ com o aumento da sua duração de 3 para 4 anos, vieram reforçar a importância e o reconhecimento da nossa especialidade dentro de portas e, a nível internacional, mostrar que Portugal conduz a formação nesta especialidade médica com mais evidente empenho que outros países, afastando-se da senda daqueles que, por motivos utilitários, persistem em considerar esta área médica como terreno indiferenciado.

Igual percurso percorreram alguns países estrangeiros que se distanciaram da denominação de Clínica Geral, optando pela de Medicina Geral ou Medicina Familiar, para assumirem uma clivagem com a falta de especialização ou de formação pós-graduada dos médicos indiferenciados que se ocupam de actividades clínicas generalistas ou mais direccionadas para certos campos de actuação.

*Directora da Revista Portuguesa de Clínica Geral
Em Portugal, há muito que esta distinção é clara na denominação dos médicos e da carreira, embora infelizmente alguns enganos grosseiros continuem a ser perpetrados pelos órgãos de decisão, quer pela contratação de médicos indiferenciados para funções de Médico de Família, quer pela demonstração falaciosa ao público carenciado de cuidados médicos, de que médicos indiferenciados, ou diferenciados em áreas completamente distintas, podem ser assemelhados e mesmo assumir as funções de verdadeiros Médicos de Família.

Mudar o nome da Associação significa assumir de uma vez por todas que os médicos que a integram são especialistas em Medicina Geral e Familiar, com um processo de graduação exigente, que é reconhecido pela sua qualidade.

Este é um passo importante e que poderá ter uma função esclarecedora, sobretudo para o exterior.

Não foi fruto de uma «crise de identidade juvenil», mas antes de um processo evolutivo deliberadamente lento que, não querendo romper abruptamente com o passado, tem vindo a admitir com orgulho que a vertente generalista da nossa especialidade se coaduna bem com a anterior denominação não pejorativa e muito dignificante de «Clínica Geral».

Sem dúvida que a nossa especialidade é generalista no seu espectro de actuação, englobando todos os problemas de saúde e todas as vertentes física, psíquica e social. ${ }^{3,4,5}$ É generalista no alvo de acção, actuando desde a pré-concepção até à gravidez, infância, maturidade, senescência, à morte e ao luto...

É generalista na abrangência, desde a promoção da saúde à prevenção da doença, até à medicina curativa, que ocupa a maior parte do nosso tempo.

É generalista no amplo campo de interesses consignado no perfil do médico de família que, como em nenhuma outra especialidade, reflecte áreas que extravasam e complementam a própria medicina, como a área da formação, da investigação, da articulação de cuida- 
dos, da advocacia dos pacientes, das funções de gestão da saúde... ${ }^{3}$

É generalista na continuidade dos cuidados, na acessibilidade e na globalidade. ${ }^{5}$

É evidente que mais este passo em frente na afirmação da nossa especialidade, bem como todas as razões enumeradas para estarmos satisfeitos com a sua forte identidade, evolução e desempenho, não devem fazer com que descuremos uma observação atenta do que se passa à nossa volta, pois uma mudança radical de enquadramento do Sistema Nacional de Saúde poderá vir a afectar, para o bem e para o mal, todos nós e, em última análise, os cuidados de saúde prestados à população.

A posição da Medicina Geral e Familiar, que ultimamente tem vindo a consolidar-se no centro do sistema de saúde, não pode nem deve desviar-se do local onde se implementou, sob pena de desperdiçarmos 35 anos de evolução duramente conseguida.
É preciso estramos atentos, vigilantes e interventivos, porque não são só os nomes que mudam... as realidades também estão em mutação.

\section{REFERÊNCIAS BIBLIOGRÁFICAS}

1. Resolução do Conselho de Ministros n.o 157/2005. Disponível em: http://www.mcsp.min-saude.pt/Imgs/content/page_106/Resolucao_Conselho_Ministros_157_2005.pdf [acedido em 14/12/2011].

2. Programa de formação do Internato de Medicina Geral e Familiar. Disponível em: http://dre.pt/pdf1sdip/2009/03/05800/0185301857 .pdf [acedido em 14/12/2011].

3. Rebelo L. O médico de família do futuro: três modelos de actuação, cinco atributos e cinco aptidões essenciais - parte II. Rev Port Clin Geral 2001 Mai-Jun; 17 (3): 249-54.

4. Mc Whinney IR, editor. A Textbook of Family Medicine. New York: Oxford University Press; 1989.

5. Jordão JG. Prefácio. In: Goroll A, May L, Mulley AG. Cuidados Primários em Medicina: Abordagem do Paciente Adulto em Ambulatório. $3^{\text {a }}$ ed. Lisboa: McGraw-Hill; 1997. p. xvii-xviii.

ENDEREÇO PARA CORRESPONDÊNCIA

director@rpcg.apmcg.pt

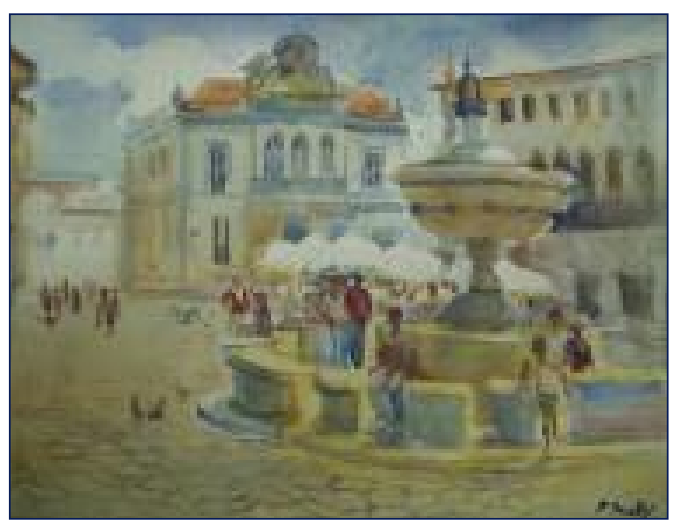

Praça do Giraldo, Évora Peg Scully

\section{PEG SCULLY}

Peg estudou pintura a óleo com Arthur Maynard no Art Institute de Ridgewood, NJ, e também na Universidade de Cincinnati. Estudou aguarela com TonyVan Hasselt, JudiWagner e Jacqui Morgan no Pratt Institute.

Sendo uma pintora de retratos, Peg também gosta de pintar a luz no envolvimento da paisagem e naturezas mortas. Gosta também de dar aulas de técnicas de pintura em aguarelas e óleos. É membro da American Watercolor Society e foi eleita membro honorário da New England Watercolor Society em 2009. Mantém igualmente uma participação activa na Newburyport Art Association e na Surroundings Gallery in Center Sandwich, NH.

Peg já ganhou vários prémios pelo seu trabalho, que pode ser visto na sua galeria junto aos Correios de Freedom, New Hampshire, assim como na Freedom Village Store e na seu website em www.pegscully.com. Na época estival, Peg faz exposições na Surroundings Gallery em Center Sandwich, NH. 